\title{
Ship Wakes and Their Potential Impacts on Salt Marshes in Jamaica Bay, New York
}

\author{
Hoda El Safty ${ }^{1,2}$ and Reza Marsooli ${ }^{1, * \mathbb{D}}$ \\ 1 Department of Civil, Environmental and Ocean Engineering, Stevens Institute of Technology, \\ Hoboken, NJ 07030, USA; helsafty@stevens.edu \\ 2 Irrigation and Hydraulics Department, Faculty of Engineering, Cairo University, P.O. Box 12211, \\ Giza 12613, Egypt \\ * Correspondence: rmarsool@stevens.edu
}

Received: 18 April 2020; Accepted: 28 April 2020; Published: 3 May 2020

\begin{abstract}
Aerial photographs and field studies have revealed a rapid deterioration of salt marshes in Jamaica Bay, New York. Past studies have linked marsh deterioration to sediment supply, water quality, storms, and sea level rise. Yet ship wakes and their potential impacts on marsh edge erosion are not understood. Here, we study ship wake transformation in Jamaica Bay and their potential impacts on salt marsh erosion. We apply short-time, Fourier transform (spectrogram) on existing water level measurements collected during 2015 and 2016. Our analysis reveals the existence of typical wake components. Among the observed wake components is a long wave component which propagates over shallow areas where short wind waves do not reach. We further implement a phase-resolving wave model to study wake transformation in the vicinity of salt marsh islands Little Egg and Big Egg and the consequent morphological changes. The selected marshes are located near a deep shipping channel and a ferry station, making them exposed to wakes of vessels with different size and sailing speed. A series of numerical experiments show that ship wakes can result in erosion spots near the border of deep shipping channels and their banks, i.e., edges of mudflats and marsh substrates. We show that the cumulative erosion increases rapidly with the number of vessels that pass through the study area. For instance, the magnitude of final bed erosion after the passage of 10 vessels is two to three times larger than that after the passage of five vessels.
\end{abstract}

Keywords: ship wakes; FUNWAVE; salt marsh erosion; Jamaica Bay

\section{Introduction}

Jamaica Bay-a back-bay in New York City—has increasingly lost its wetlands over the past decades. For example, salt marshes in the bay have lost $0.4 \%$ of their area per year between 1924 and 1974, 1.4\% per year between 1974 and 1994, and 3.0\% per year between 1994 and 1999 [1]. Previous studies have linked the salt marsh erosion to sea level rise, insufficient sediment supply, and storm surges and waves [2-7]. However, the effects of manmade causes such as ship wakes are not studied yet. We hypothesize that ship wakes are a non-negligible cause of salt marsh erosion in Jamaica Bay. Here, we analyze measurements and perform numerical experiments to gain a first-order understanding of the characteristics of ship wakes in Jamaica Bay and their potential impacts on marsh erosion.

Jamaica Bay is a coastal embayment that comprises the largest tidal wetland community in the New York metropolitan area. Salt marshes in the bay provide ecosystem services such as maintaining a healthy water, providing nursery and habitat for fisheries, and mitigating flood hazards [8,9]. The bay has lost over 4856 ha of its former 6475 ha of wetlands since the mid-1800s [10]. To date, there is no consensus on the cause of salt marsh erosion in Jamaica Bay. Previous studies have investigated 
the relation between salt marsh health and sediment budget and transport, sea level rise, storms, temperature, and nitrogen input.

According to [11,12], they analyzed the aboveground green biomass in Jamaica Bay and reconstructed the sediment history. They found a noticeable loss of mineral sediment and an increase in organic sediments in Yellow Bar and JoCo marsh islands because of urbanization activities. Changes in sediment classification/structure weaken the marshes and put them in risk especially with sea level rise. In [13], they studied geomorphological restoration and resilience in Jamaica Bay using field surveys to provide data for numerical models. They studied the effects of sea level rise and human impacts on accumulating sediment and organic matter. In [14], they estimated sediment flux into Jamaica Bay through Rockaway Inlet using shipboard, moored vertical profiling current meters, optical backscatter, and laterally profiling. They found a net input of sediment into the bay during spring tides and storms. In [15], they studied the morphological changes of salt marshes in Jamaica Bay during Hurricane Sandy in 2012. They found that morphological changes caused by Sandy were complex and spatially heterogeneous, and salt marches inside the western part of the bay showed erosion while the marshes in the eastern part of the bay showed deposition. Marshes in the western part of the bay are likely to be more vulnerable to storm than marshes in the eastern part of the bay. Moreover, [16] found that urban development in the bay makes marshes structurally weak, owing to a dramatic reduction in mineral sediments and increase in organic sediments. The past studies, including those cited here, have showed that different natural and human-induced factors contribute to the health of salt marshes in Jamaica Bay. Although not evaluated yet, ship wakes could be another contributing factor to the marsh erosion in the bay.

In many estuarine and fetch limited environments, vessel-generated waves (ship wakes) are often considered as another cause of shoreline change and retreat, particularly in areas that commercial and recreational boat traffic is frequent [17-26]. The level of importance of vessel-generated waves for the shoreline dynamics widely varies from being a significant control $[19,23,26]$ to no impact [27]. Ship wake energy depends on the vessel length, water depth, vessel speed, and channel shape [28,29], and could result in shoreline erosion $[18,19]$ and sediment resuspension and transport that temporarily change the water turbidity. According to [30], even small recreational vessels within $10 \mathrm{~m}$ of the shoreline could produce wakes that could result in shoreline erosion. The effects are stronger where ship wakes could not dissipate their energy before reaching the shoreline, for example, in shallower water or in narrower waterways which exist in Jamaica Bay [31]. In the littoral zone of Lake Constance, [32] found that resuspension of sediment which occurred $54 \%$ of the observation time were caused by vessel waves. In [33], the author identified different erosion patterns to marshes shoreline in Rehoboth Bay, Delaware and related the erosion rate with the wave power through a regression analysis.

According to [34], the erosive force of ship wakes could be due to a longer period and height of wakes compared to wind waves even though ship wakes represent only a small portion of the total wave energy. In [34], they studied Fort Pulaski National Monument salt marches retreat and found that waves generated by vessels accounted for $5 \%$ of accumulative wave energy and accounted for $25 \%$ of the cumulative wave force due to their longer periods and larger heights. In [35], the authors used a time-frequency technique to analyze the characteristics of ship wakes collected in Tallinn Bay, the Baltic Sea. They found that a train of low frequency waves appears almost $10 \mathrm{~min}$ before the most energetic waves and this wave train has the characteristics of chirp signal. They concluded that the wave train consists of solitary waves rather than dispersive waves. In [36], the author observed that in low length-based Froude numbers, the wake spectrogram has high intensity values at lower frequencies compared to high length-based Froude number cases.

The goal of this study is to evaluate characteristics of ship wakes in Jamaica Bay and their potential impacts on two selected salt marsh islands, Little Egg and Big Egg. These marsh islands are exposed to relatively heavy vessel traffic because of the presence of a nearby ferry station, i.e., Rockaway Ferry landing point. Using a series of numerical experiments, simulated based on a Boussinesq-type wave model, we discuss the potential impacts of ship wakes on the marsh erosion. The paper is organized 
as follows. We describe in Section 2 an existing dataset of water surface measurements previously collected in Jamaica Bay. Methods that we use for data analysis and numerical modeling are also described. Results are presented and discussed in Section 3. Conclusions are presented in Section 4.

\section{Data and Methods}

\subsection{Study Area}

Jamaica Bay is a saline to brackish, nutrient-rich estuary covering about $100 \mathrm{~km}^{2}$, with more than 25 federal, states, and local agencies have some jurisdictional responsibilities in the bay, and numerous private and public entities have strong ties to it. Jamaica Bay has an averaged semidiurnal tidal range of $1.5 \mathrm{~m}$ and a residence time of up to three weeks $[37,38]$. While the bay's average water depth is $4 \mathrm{~m}$, the average depth of navigation channels ranges from 10 to $15 \mathrm{~m}$. The center of the bay comprises several salt marsh islands. The ecosystems in these marshes are very rich including different types of plants, dominated by Spartina Alterniflora (salt-water cord grass). Since 1951, approximately $60 \%$ of the bay's salt marshes have converted into mudflats.

In past years, a significant amount of effort was taken to identify potential marsh restoration locations in the bay. For Example, a pilot restoration project was initiated by the U.S. National Park Service (NPS) in 2003 on 2-acre of Big Egg marsh island by using "thin-layer" sediment spraying to raise the marsh elevation [39]. Another project that was funded by multiple agencies, including New York City Department of Environmental Protection [39], was completed at 70-acres of Elders Point East in 2006. Restoration projects have been also completed at Yellow Bar and Elder's Point West, [40].

A potential overlooked hazard to salt marshes in Jamaica Bay is vessel-generated waves (ship wakes) and their capability to cause sediment resuspension, transport, erosion, and morphological changes. Vessel traffic in Jamaica Bay can be considered relatively high since the bay is home to several marinas and boating clubs and a destination of ferries and cruises. There are different vessel types that sail inside the bay daily, e.g., tugboats, passenger boats, and high-speed crafts. The typical length and width of these boats are, respectively, in the range of 20-30 m and 5-10 $\mathrm{m}$ and the sailing speed ranges from 3 to 25 knots (according to ship Automatic Identification System, AIS).

We select Big Egg and Little Egg salt marsh islands to study ship wake threats to salt marshes. These marsh islands are located in the southern portion of the bay (Figure 1) and are exposed to heavy boat traffic in Beach Channel. Moreover, these salt marshes have experienced a net loss in area in the past few decades.
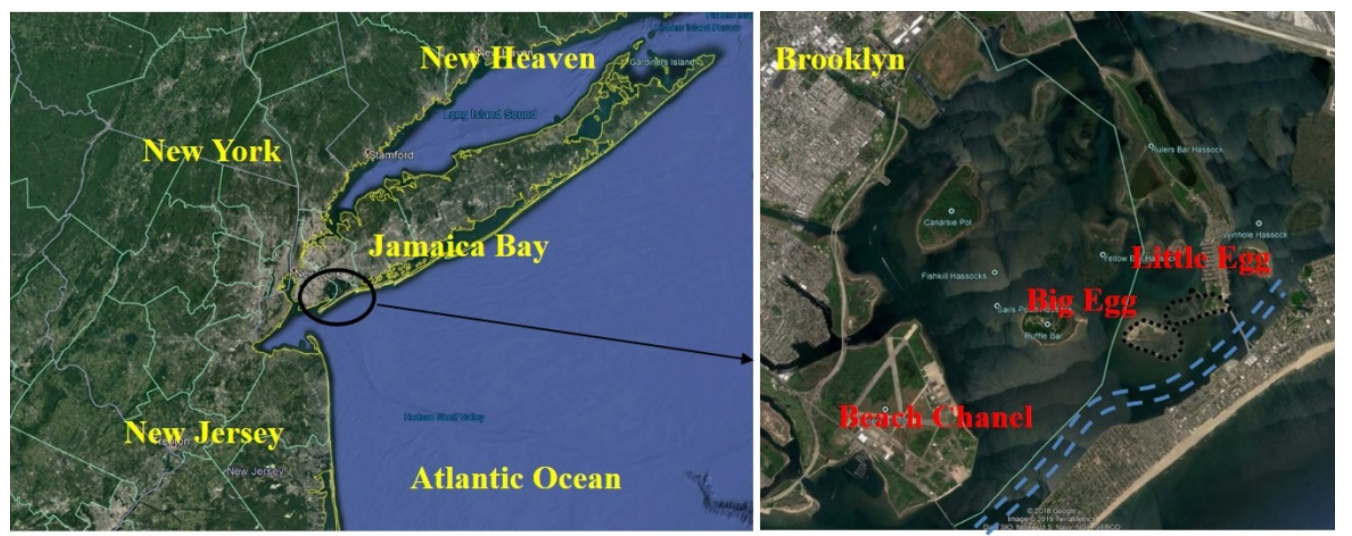

Figure 1. Geographic locations of Jamaica Bay (left panel) and Big and Little Egg marsh islands (Right Panel). The blue dashed lines show the navigation route in Beach Channel.

\subsection{Wake Measurements}

We evaluate the characteristics of ship wakes in Jamaica Bay using an existing dataset of measured water surface elevation collected at multiple locations in the bay during a past study (we obtained 
measurements by personal communications with the study team, led by Dr. Robert Chant, from Rutgers University, New Brunswick, NJ, USA). At some locations, data are short and noisy, not adequate for ship wake analysis. We use the collected data at the bay's inlet near Rockaway Point (RP) and in the North Channel near Canarsie Pier (CP), shown in Figure 2. The measurements were collected using Acoustic Wave and Current (AWAC) $1000 \mathrm{KHz}$ sensors which were programmed to burst sample every $17 \mathrm{~min}$. Burst sample consisted of 2048 samples (at $2 \mathrm{~Hz}$ ) for water surface track. Data at RP were noisy because of high vessel traffic in the bay's inlet. The measurements were collected over 8 deployments at CP and 9 deployments at RP from 20th of May 2015 to 25th of August 2016. Through visual data inspection, we choose time periods with clear ship wake signals.

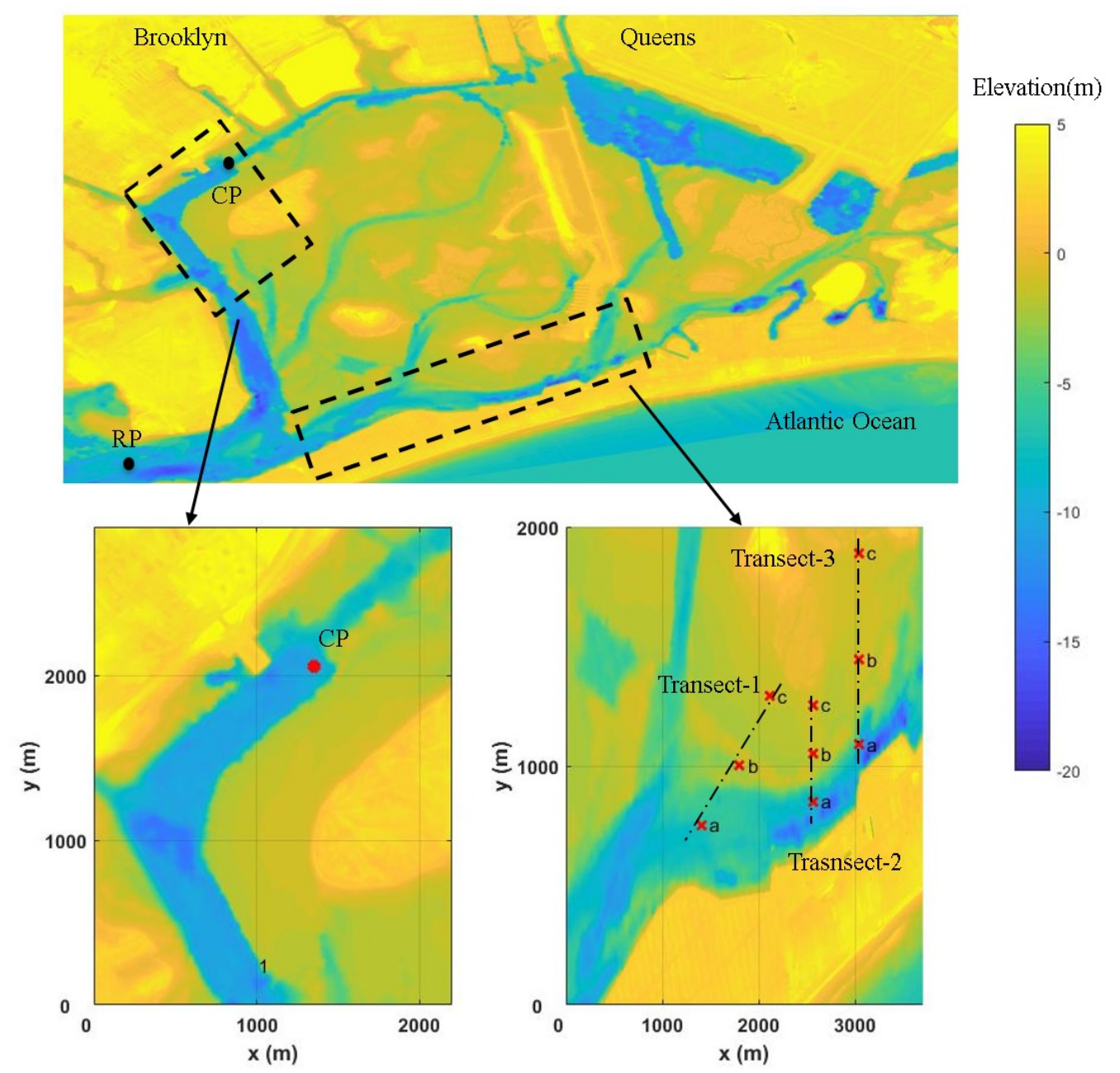

Figure 2. Topo-bathy of Jamaica Bay (top panel) and computational domains of the numerical model (bottom panels). Units are in meter. Vertical datum is mean sea level. Dashed-rectangles represent the boundaries of computational domains (bottom left panel for ship wake model evaluation; bottom right panel for wake-induced marsh erosion numerical experiments). Solid circles represent the location of wake measurement (labeled as CP and RP). Dash-dotted lines and cross signs (labeled a, b, and c) represent locations where model results are presented and discussed.

\subsection{Ship Wake Analysis Approach}

Ship wake studies usually determine the wake hydrodynamic regime based on two non-dimensional parameters. The first parameter is a depth-based Froude number which is defined as the ratio of the vessel speed and the square root of the gravitational acceleration multiplied by the water depth. The second parameter is the length-based Froude number defined as the ratio of the vessel speed and the square root of the gravitational acceleration multiplied by the vessel length. For a 
depth Froude number of up to 0.6, [41] found that gravity waves generated by a moving disturbance in deep waters can be characterized with the classic pattern of diverging and transverse waves. The depth Froude number increases as the water depth decreases or the vessel speed increases, resulting in longer waves that interact with the bottom and, in turn, changes in wake properties. As the depth Froude number reaches the critical value of 1 , transverse waves disappear.

Based on Kelvin's analysis, a moving vessel generates transverse and divergent waves that exist in a wedge of 39 angle. The wave pattern formed by these transverse and divergent waves depends on the vessel speed. Transverse waves have the same propagation direction as the vessel heading, whereas divergent waves propagate oblique to the vessel heading. Recent studies [42,43], highlighted the complexity of ship wake structure and showed that Kelvin wake properties may substantially change at high Froude numbers.

Spectrograms are used in signal processing to decompose signals into wave components of different frequency. By applying linear wave theory, [44] showed that, for small amplitude waves, the spectrogram of a steadily moving vessel has two linear components: a sliding-frequency mode (chirp) and a constant-frequency mode corresponding to divergent and transverse wave components, respectively. However, by analyzing wakes generated by high speed ferries in Gulf of Finland, i.e., $0.5 \mathrm{~m}$-high wakes, [44] found and classified five wake components in the spectrogram, two linear components and three other components including precursor solitary wave (PW), leading wave (LW), and low frequency wave (LW). In [45], they were able to offer some evidence that two of the additional wake components (PW and LW) were a result of wave shoaling and nonlinear effects caused by ship wakes approaching the shore. The cause of the precursor solitary wave and leading wave has been attributed to the nonlinear effects of ship hull and wave shoaling. The leading wave system contains contribution from the cusp wave system, but probably also elements of transverse and divergent waves.

In the present study, we apply short-time Fourier transform, spectrogram, to field data collected in Jamaica Bay to study transformation of ship wakes in the bay. The data are first de-trended to remove the mean and any linear trend. The filtered data are then processed by using the spectrogram function in MATLAB and applying hamming windows of $25 \mathrm{~s}$ and an overlap of $20 \mathrm{~s}$.

\subsection{Numerical Model}

We utilize the total variation diminishing (TVD) version of the fully nonlinear Boussinesq wave model (FUNWAVE) to numerically simulate ship wakes and wake-induced morphology changes. FUNWAVE-TVD [46] is a high-order adaptive time-stepping solver for the fully nonlinear Boussinesq model of [47]. We run the model in parallel mode with its coupled hydrodynamic, ship-wake, sediment transport, and morphological modules. The hydrodynamic module solves the hybrid finite-volume and finite-difference scheme for fully nonlinear Boussinesq equations with incorporation of moving reference level as [48]. The module solves the following depth-averaged conservation and horizontal momentum equations [49],

$$
\begin{aligned}
\eta_{t}+\nabla \cdot \mathbf{M} & =0 \\
\mathbf{M}_{t}+\nabla \cdot\left[\frac{\mathbf{M M}}{H}\right]+\nabla\left[\frac{1}{2} g\left(\eta^{2}+2 h \eta\right)\right] & =\mathbf{V}_{d i s}+g \eta \nabla h-S_{\text {ship }}-S_{b r k}
\end{aligned}
$$

where $\eta$ is the water surface level, $t$ is the time (subscript $t$ means derivative with respect to time), $g$ is the gravitational acceleration, $\mathbf{M}$ is the horizontal volume flux calculated as $H\left\{u_{\propto}+\bar{u}_{2}\right\}$ with $H$ being the total water depth (summation of still water depth $h$ and water surface level $\eta$ ), $u_{\alpha}$ the velocity at a reference elevation, and $u_{2}$ the depth-dependent correction of velocity (see [46]). $\mathbf{V}_{d i s}$ is the dispersive Boussinesq terms [46]. $S_{b r k}$ is a dissipation term due to the artificial eddy viscosity [49]. $S_{\text {ship }}$ is a pressure source term for ship-wake generation. The ship-wake generation mechanism follows [50-52]. The ship wake source term represents the gradient in the pressure on the water surface. The pressure 
is a function of time and horizontal space, and is equal to zero outside a rectangular region with a length of $\mathrm{L}$ and width of $\mathrm{R}$. Inside this region, the pressure is calculated as the following equations [49]

$$
\begin{gathered}
p_{a}(\tilde{x}, \tilde{y})=\operatorname{Pf}(\tilde{x}, t) q(\tilde{y}, t) \\
f(\tilde{x}, t)=\left\{\begin{array}{cc}
\cos ^{2}\left[\frac{\pi\left(\left|\tilde{x}-x^{*}(t)\right|-\frac{1}{2} \alpha L\right)}{(1-\alpha) L}\right], & \frac{1}{2} \alpha L<\left|\tilde{x}-x^{*}(t)\right| \leq \frac{1}{2} L \\
1, & \left|\tilde{x}-x^{*}(t)\right| \leq \frac{1}{2} \alpha L
\end{array}\right. \\
q(\tilde{y}, t)=\left\{\begin{array}{cc}
\cos ^{2}\left[\frac{\pi\left(\left|\tilde{y}-y^{*}(t)\right|-\frac{1}{2} \beta R\right.}{(1-\beta) R}\right], \frac{1}{2} \beta R<\left|\tilde{y}-y^{*}(t)\right| \leq \frac{1}{2} R \\
1, & \left|\tilde{y}-y^{*}(t)\right| \leq \frac{1}{2} \beta R
\end{array}\right.
\end{gathered}
$$

where $\left(x^{*}, y^{*}\right)$ is the center point of the pressure disturbance, $(\tilde{x}, \tilde{y})$ is the coordinate system for the pressure disturbance which may be rotated by an angle relative to the Boussinesq coordinate system $(x, y)$, and $\alpha$ and $\beta$ are parameters that represent the shape of the ship's draft. More details on the model's ship wake module can be found in [49].

The morphological module of FUNWAVE calculates bed changes based on the sediment continuity equation and uses time-averaged pickup and deposition rates to compute morphological changes. The sediment transport module is based on the quasi-steady flow assumption, which is suitable for model applications to ship-wake-induced sediment transport predictions [53]. It also includes both suspended and bed load sediment transport. The model calculates morphological changes using the following sediment continuity equation,

$$
\frac{\mathrm{dZ}}{\mathrm{dt}}=\frac{1}{1-\mathrm{n}}\left(\mathrm{P}-\mathrm{D}-\nabla \cdot \mathbf{q}_{b}\right)
$$

where $Z_{b}$ is the time-averaged depth change, $\mathrm{n}$ is the sediment porosity, $\mathrm{p}$ and $\mathrm{D}$ are the pickup (erosion) and deposition rates, and $\mathbf{q}_{b}$ is the bed load flux vector. The pickup and deposition rates are calculated based on the $[54,55]$, respectively. These formulae are applicable to non-cohesive sediment particles. Sediment depositions in our study domain (in Beach Channel and edges of Little Egg and Big Egg islands) are mainly non-cohesive sediment. Measurements of mud content show that mud forms less than $30 \%$ of sediment depositions in the Beach Channel and Little Egg and Big Egg marsh islands [56]. The bed load flux $\mathbf{q}_{b}$ in FUNWAVE is calculated based on the Meyer-Peter and Muller formula [57]. The representative diameter of sediment particles in the bay is set to $0.18 \mathrm{~mm}[15,58]$. This representative diameter is smaller than the range of sediment size considered in the derivation of the Meyer-Peter and Muller formula. However, previous studies have shown that the Meyer-Peter and Muller formula satisfactory performs for sediments with a smaller grain size than the size range used in the derivation of this formula $[59,60]$.

The deposition rate is calculated based on the suspended sediment load estimated from the following depth-averaged transport equation for non-cohesive sediment

$$
(\overline{\mathrm{c}} \mathrm{H})_{\mathrm{t}}+\nabla_{\mathrm{h}} \cdot(\overline{\mathrm{c}} \mathbf{M})=\nabla_{\mathrm{h}} \cdot\left(\mathrm{KH}\left(\nabla_{\mathrm{h}} \overline{\mathrm{c}}\right)\right)+\mathrm{P}-\mathrm{D}
$$

where $\overline{\mathrm{c}}$ is the non-dimensional depth-averaged sediment concentration normalized by sediment density, $k$ is the horizontal sediment diffusion coefficient calculated based on Elder formula [61]. Cohesive sediment transport is not considered in the present study.

The morphological model adopts an avalanching algorithm that controls the maximum slope of the seabed and shorelines. The algorithm sets the maximum slope to the sediment repose angle. Depending on the sediment particle size, the response angle is between 30 and 40 degrees [62]. 
The performance of the sediment transport and morphological modules of FUNWAVE-TVD has been previously evaluated against laboratory data and field measurements. For example [63], the authors conducted simulations to replicate laboratory experiments of $[64,65]$. Their model results were similar to observations. Model capabilities to simulate ship wakes have been successfully evaluated based on waves generated by fast vessels moving in a narrow channel with slopping beaches on both sides of the channel $[49,53]$. The Kelvin wake patterns behind the vessel and waves reflected from the beaches were well predicated. The soliton generation with the same Froude number and wave breaking concentrated at the first observed soliton front were captured by the model.

The performance of the model to simulate wake-induced morphological changes has not been evaluated yet, because of the lack of measurements. There is currently no measured wake-induced erosion data in Jamaica Bay. Here, we evaluate the ship-wake model performance using existing water surface measurements in the bay. The lack of information on the type of vessels that entered the study area during the period of measurements restricts conducting the model evaluation based on individual wake characteristics. Instead, we simulate wakes generated by typical vessels that enter the study area and qualitatively compare the characteristics of the modeled wake groups with measurements. We evaluate the model performance against wake measurements at the measurement site $\mathrm{CP}$ where the presence of wakes is clearly visible in the measurements. The extent and bathymetry of the computational domain used in the model is shown in the lower left panel of Figure 2. The computational grids have a resolution of $1 \mathrm{~m}$ in both longitudinal and lateral directions. The time step is determined based on the CFL stability condition. We set the Manning friction coefficient to 0.2 for vegetated areas and 0.03 for open waters.

We further implement the model to quantify effects of ship wakes on salt marsh islands Little Egg and Big Egg. The computational domain used in numerical experiments of wake-induced erosion is shown in the lower right panel of Figure 2 (to have smaller domains and save computational cost, this computational domain is different from the domain used for model evaluation). The water level in all simulations is set to the mean sea level. Simulations are carried out for different vessel size and sailing speeds to quantify their effects on the wake height and marshes. The selected speed and size of vessels resemble typical boats that enter the study area in a daily basis, e.g., Rainbow Cruise which is a $23 \mathrm{~m}$ long and $8 \mathrm{~m}$ wide vessel (Figure A1 in Appendix A). To study commutative impacts of wakes on marshes, we also carry out experiments that account for the passage of a fleet of 10 vessels. The list of numerical experiments is summarized in Table 1.

Table 1. Numerical experiments to quantify wake effects on marshes. In experiments with the number of vessels greater than one, a vessel enters the domain every $5 \mathrm{~min}$.

\begin{tabular}{cccc}
\hline Experiment & Vessel Size (m) (Length $\times$ Width) & Average Sailing Speed (Knot) & Number of Vessels \\
\hline 1 & $23 \times 8$ & 5 & 1 \\
2 & $23 \times 8$ & 15 & 1 \\
3 & $23 \times 8$ & 5 & 10 \\
4 & $23 \times 8$ & 15 & 10 \\
5 & $15 \times 5$ & 5 & 1 \\
6 & $15 \times 5$ & 15 & 1 \\
7 & $15 \times 5$ & 5 & 10 \\
8 & $15 \times 5$ & 15 & 10 \\
\hline
\end{tabular}

\section{Results and Discussion}

\subsection{Characteristics of Measured Ship Wakes}

A series of measured wake events observed during the first and eight deployments at CP are analyzed. The wake events during the first deployment were observed in 22nd May at $10 \mathrm{am}$, 2nd June at $4 \mathrm{pm}$, and 6th June at 12 am (Figure 3). The wake events during the eighth deployment were observed in 22nd July at 6:30 pm, 26th July at 6 am, and 27th July at $1 \mathrm{pm}$ (Figure 4). The measured water level 
time series during these events are shown in the top panels of Figures 3 and 4 . The short-time Fourier transforms, spectrograms, are shown in the bottom panels. In most cases, the observed wake heights range from 6 to $10 \mathrm{~cm}$ followed by wave groups.
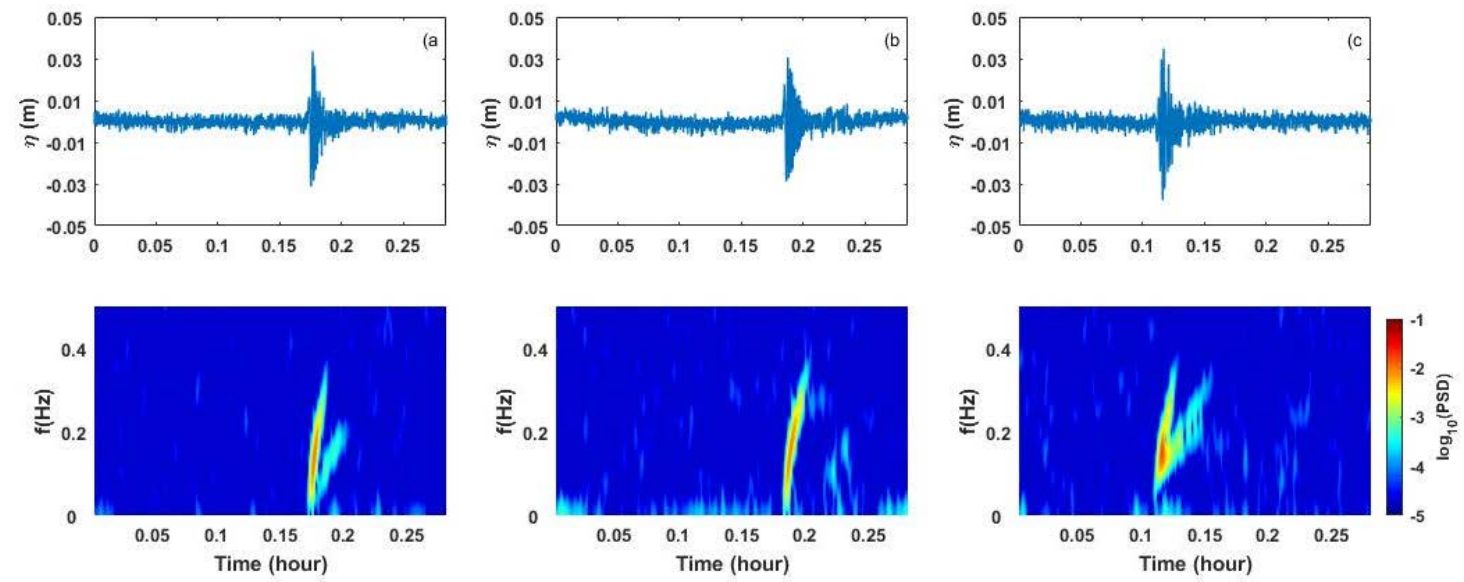

Figure 3. Selected wake events observed during the first deployment at CP. Top panels show the 17-min burst time series of water surface elevation. Bottom panels show the wakes Spectrograms. (a) Wake event in 22nd May at $10 \mathrm{am}$, (b) wake event in 2nd June at 4pm, and (c) wake event in 6th June at 12 am. $\eta$ is the water level and $\mathrm{f}$ is the frequency.
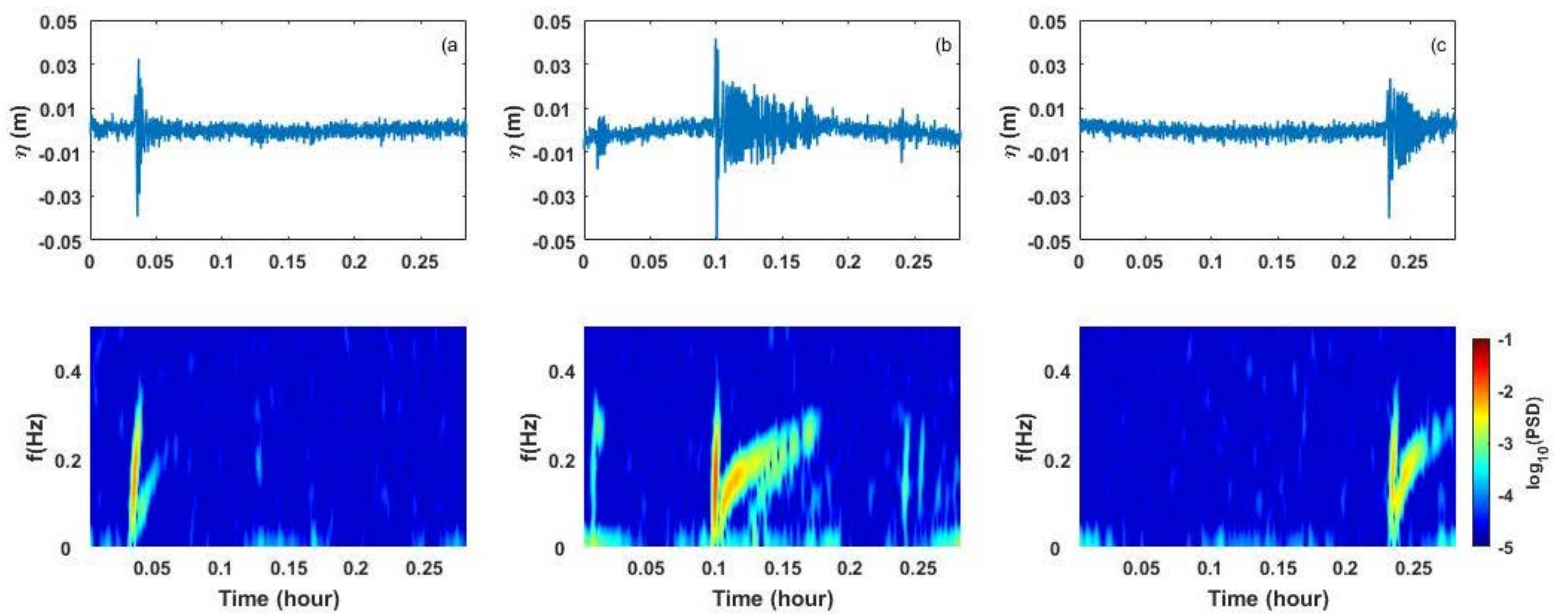

Figure 4. Selected wake events observed during the eight deployment at CP. Top panels show the 17-min burst time series of surface elevation. Bottom panels show the wakes Spectrograms. (a) Wake event in 22nd July at 6:30 pm, (b) wake event in 26th July at 6 am, and (c) wake event in 27th July at $1 \mathrm{pm}$.

The spectrograms of observed wakes (bottom panels in Figures 3 and 4) show the frequency of these wake components varies from approximately $2 \mathrm{~s}$ to about $20 \mathrm{~s}$. The wave group containing the most energetic waves creates a strong signal with wide spectrum, frequencies ranging from $0.05-0.4 \mathrm{~Hz}$. This effect is consistent with transformation of nonlinear long waves during shoaling and before breaking. Also, a slightly weaker signal can be identified at lower frequencies, in the range from $0.02-0.05 \mathrm{~Hz}$ that arrives simultaneously with the strongest wake signal. The waves after the most energetic wave produce a complex pattern in the spectrogram. In many situations, this pattern consists of two branches that reflect Kelvin wake classical components. However, a slight change in their frequency could be associated with their generation in the confined area, in the measurement location.

Spectrograms of wakes observed during the first deployment (bottom panels in Figure 3) are much like the spectrogram representation of Kelvin wake components with stronger divergent component 
as shown in first and third wakes (panels a and c) compared to that for the second wake (panel b). A possible cause of the observed patterns is a large depth Froude number. The spectrograms also indicate a weak existence of wake components $\mathrm{PW}$ and LF, and a strong absence of wake component $\mathrm{LW}$. A possible reason for this pattern is the small wake amplitude. In [36], they associated the formation of LW component with nonlinear waves, probably higher wake amplitude. However, because of the lack of information about the exact characteristics and speed of vessels in our study area that generated these wakes, it is not feasible to draw explicit relations between vessels type and speed and properties of the observed wakes.

Spectrograms of wakes observed during the eight deployment (bottom panels in Figure 4) show that the divergent wave component is stronger as the first deployment, discussed above, and also show the existence of LW associated with nonlinear waves. The second wake event (panel $b$ ) can be interpreted as the largest wave that occurs at the beginning of the wake wedge and then followed by the wave group that appears for a longer time. The existence of PW and LF components are clear in the spectrograms as well. With more field data, better understandings of various wake components and their transformations could be drawn.

\subsection{Model Evaluation}

Based on the ship automatic identification system (AIS), www.marinetraffic.com, we estimate the features of the potential vessel that could be near the measurement site during the time that measurements were collected. We consider vessels that pass through the North Channel near the wake measurement site at $\mathrm{CP}$ (North channel is the deep navigating channel where $\mathrm{CP}$ is located). The potential vessel is Pink Lady which is a tugboat with $20 \mathrm{~m}$ in length and $8 \mathrm{~m}$ in width. The typical path and speed of Pink Lady are shown in Figure A2. We implement the model to simulate water surface elevation and generate the spectrogram at $\mathrm{CP}$, as shown in Figure 5. The modeled wake height is in the order of $10^{-2} \mathrm{~m}$ which is consistent with the order of magnitude of observed wakes at $\mathrm{CP}$ (see, e.g., Figure 3). The maximum modeled and measured wake heights are approximately $10 \mathrm{~cm}$ and $8 \mathrm{~cm}$, respectively. The model-based spectrogram (bottom panel in Figure 5) shows that the pattern in the modeled wave group following the wake is consistent with that observed in the field (Figure 3c).

Similar to observations in the field, the model-based spectrogram shows a stronger divergent wave component than the transvers component. Also, the model-based spectrogram indicates the existence of wave components PW and LF with a weak existence of LW. Based on energy calculations of each component of the wave, [44] showed that the leading wave system contributes over $80 \%$ of the total wake energy. Both observed and modeled spectrograms show the existence of strong leading waves, containing more than $50 \%$ of wakes energy, which are potential hazards to salt marshes inside Jamaica Bay.
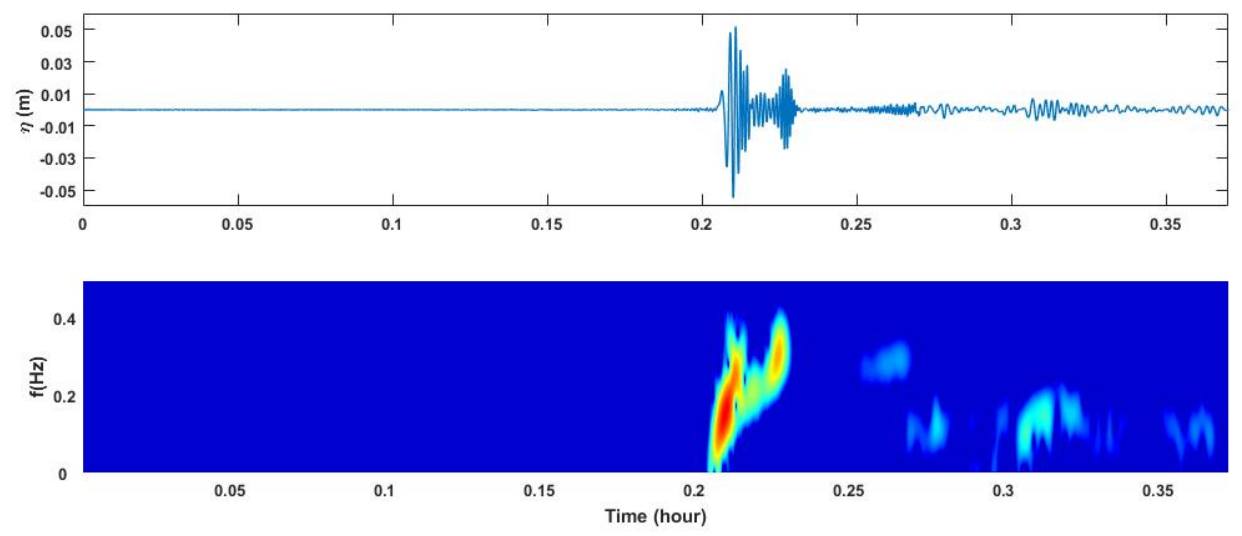

Figure 5. Modeled water surface elevation time series (top panel) and spectrogram (bottom panel) of wakes generated by the Pink Lady vessel at the CP measurement location. 


\subsection{Numerical Experiments}

We implement the model to simulate numerical experiments listed in Table 1. Wake height transformation along three transects near the Big and Little Egg marsh islands are presented and discussed (see Figure 2 for the location of transects). In experiments that consider the passage of multiple vessels, the time interval between each vessel entering the study area is set to $5 \mathrm{~min}$. We also examined time intervals of $1 \mathrm{~min}$ and $10 \mathrm{~min}$. In contrast to a 1-min time interval, it was found that 5- and 10-min time intervals are sufficient to obtain a calm water surface prior to the arrival of the next group of wakes. However, the 5-min time interval resulted in less computational times, and thus is used in the numerical experiments discussed in this paper. Figure 6 shows an example of the temporal variation of wake height at the location of model output stations $a, b$, and $c$ along the three transects (see Figure 2 for the location of time series stations).

Irrespective of the vessel size, results of the numerical experiments show that wake heights generated by a slow vessel (i.e., experiments 1 and 5) are negligible (wakes nearly completely dissipate before reaching marshes). On the other hand, for a vessel moving with a speed of 15 knots (i.e., experiments 2 and 6), model results indicate that wakes generated by the large and small vessels, respectively, reach a maximum height of $1.2 \mathrm{~m}$ and $0.5 \mathrm{~m}$ at the deepest part along transect 1 and gradually become smaller as they propagate to shallower waters (Figure 7). On the mudflats and near marsh edges, e.g., in the vicinity of station c, the maximum wake height is about $0.08 \mathrm{~m}$, regardless of the size of the vessel. The maximum wake heights generated by the large and small vessels at the deepest parts along transects 2 and 3 are about 2 and $1.9 \mathrm{~m}$ which are larger than those generated along transect 1 . This is due to the presence of deeper navigation channels. Salt marshes in the center of Jamaica Bay are surrounded by deep navigation channels that, at some areas such as in North and Beach Channels, are as deep as 15-20 m. Marsh edge erosion and, thus, marsh deterioration could be a long-term consequence of large ship wakes generated in these deep channels. It is known that the amount of ship wake energy is not only a function of the size and speed of vessels, but also the frequency of vessels $[29,30]$.

Results of the large vessel experiments show that the wake height reduces about $89 \%$ as wakes travel from station a to station $\mathrm{b}$ along transects 1 and 2 . The water depth changes from $7 \mathrm{~m}$ to $2 \mathrm{~m}$ over $450 \mathrm{~m}$ along transect 1 and from $8.3 \mathrm{~m}$ to $2 \mathrm{~m}$ over $250 \mathrm{~m}$ along transect 2 . Similarly, along transect 3 , the height of ship wakes reduces $89 \%$ while the wakes propagate from station a to station $b$ where the water depth changes from $9 \mathrm{~m}$ to $1.2 \mathrm{~m}$ over approximately $300 \mathrm{~m}$. It is noticeable that the wakes sustain more energy while traveling from the deep water toward the edge of the marshes along transects 1 and 2 than transect 3 . This is mainly due to the presence of wider mudflat areas with shallow water along transect 3, which results in wake energy dissipation due to bottom friction and depth-induced breaking.

The cumulative bed elevation change induced by a fleet of 10 vessels (experiments 4 and 8 ) is shown in Figure 8. Results show that the extent of areas that experience a decrease in the bed elevation change, i.e., erosion, is smaller than the extent of areas with an increase in the bed elevation change, i.e., deposition. However, the magnitude of erosion in eroded areas is one order of magnitude larger than the magnitude of deposition in accreted areas. Large amounts of erosion are calculated at the boundary of deep shipping channels and their banks, i.e., near the edge of mudflats and marsh islands. Larger vessels cause more intense erosion and the erosion spots extend closer to the edges of Big Egg marsh island.

The magnitude of erosion nonlinearly increases as the number of vessels passing the study area increases. Figure 9 shows the acceleration of erosion rate after the passage of 10 vessels. The magnitude of the final bed erosion after the passage of 10 small or 10 large vessels is two to three times larger than that after the passage of 5 vessels. Model results, not shown here, indicate that vessels with a slow sailing speed (experiments 3 and 7) result in a negligible bed elevation change. Similarly, a negligible elevation change was also calculated for experiments that consider the passage of a single vessel (experiments 1,2,5, and 6). The results presented here suggest that cumulative effects of ship wakes could result in large magnitudes of erosion near the edge and over the mudflats and marsh islands 
over time. However, the sailing speed of vessels has a significant impact on the magnitude of erosion. While slow moving vessels generate small wakes, fast vessels could generate large ship wakes that result in erosion at the edge of deep channel banks, e.g., mudflat and marsh edges. These results emphasis the need for further detailed studies that integrate field measurements with numerical modeling to better understand short- and long-term effects of ship wakes on morphological changes in Jamaica Bay.
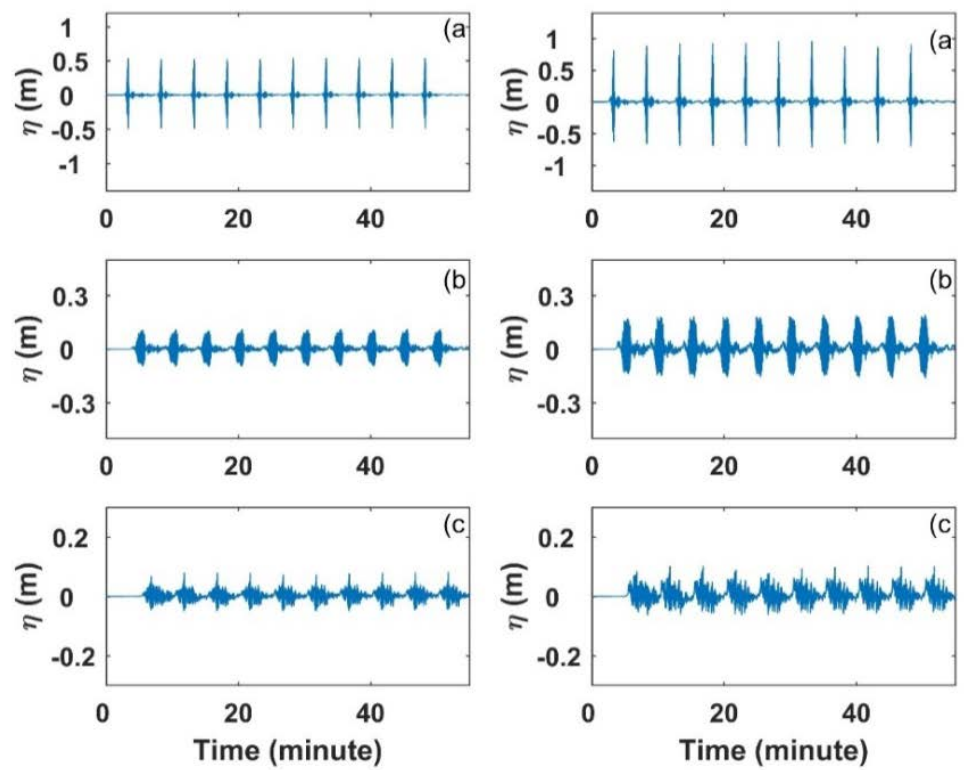

Figure 6. Time series of water surface elevation at stations a, b, and c along transect-1. Results are for experiments with 10 small (left) and 10 large (right) vessels with a sailing speed of 15 knots (i.e., experiments 8 and 4). The time between each vessel entering the study area is $5 \mathrm{~min}$.

(a) Transect-1
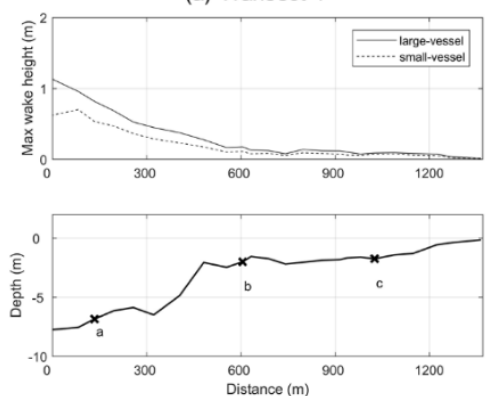

(b) Transect-2
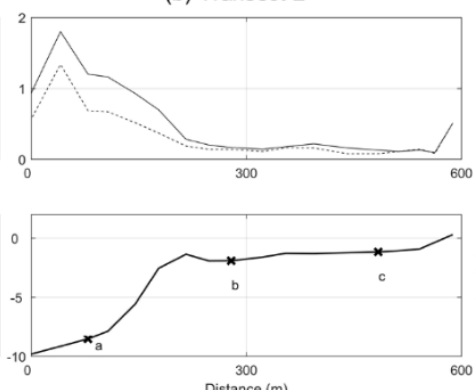

(c) Transect-3
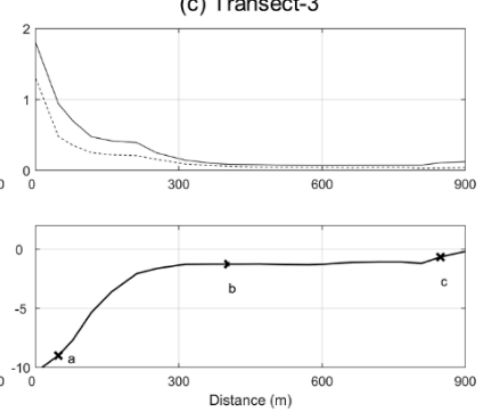

Figure 7. Cross shore profiles of maximum wake height (top panels; solid lines for experiments with large vessel and dashed lines for small vessel) and bathymetry (bottom panels) along transects 1, 2, and 3. Results are for single vessel experiments with a speed of 15 knots. Points $a, b$, and c are the locations of model output stations. 

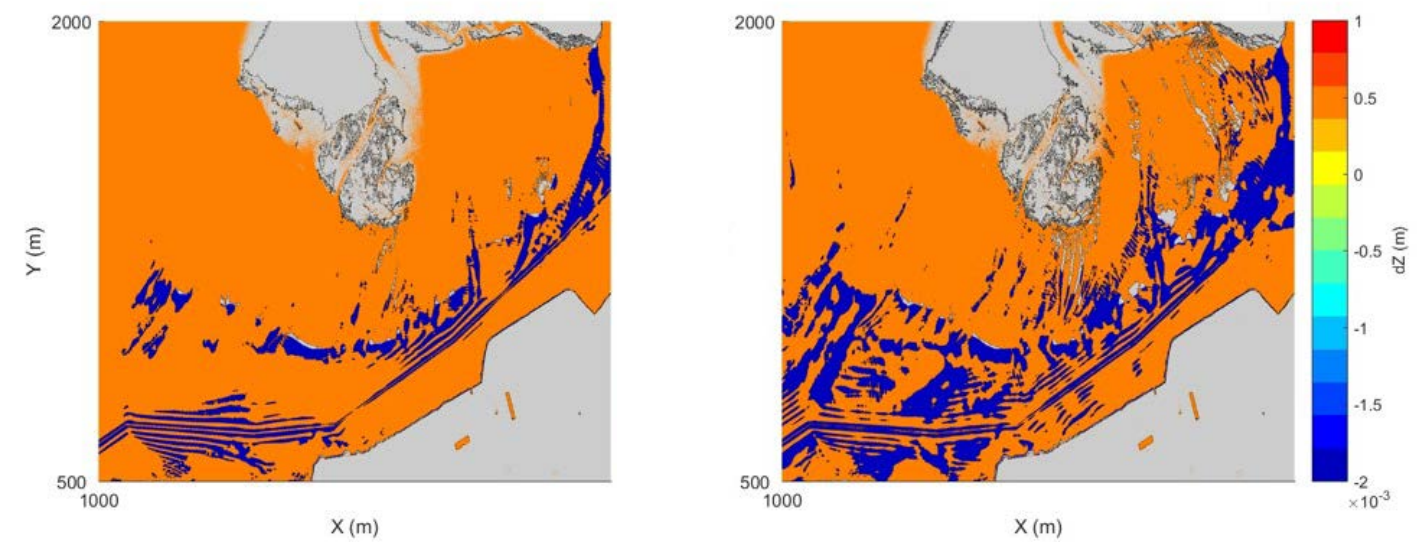

Figure 8. Spatial distribution of cumulative wake-induced bed elevation changes after the passage of 10 small (left panel) and 10 large (right panel) vessels. The vessel sailing speed is 15 knots.
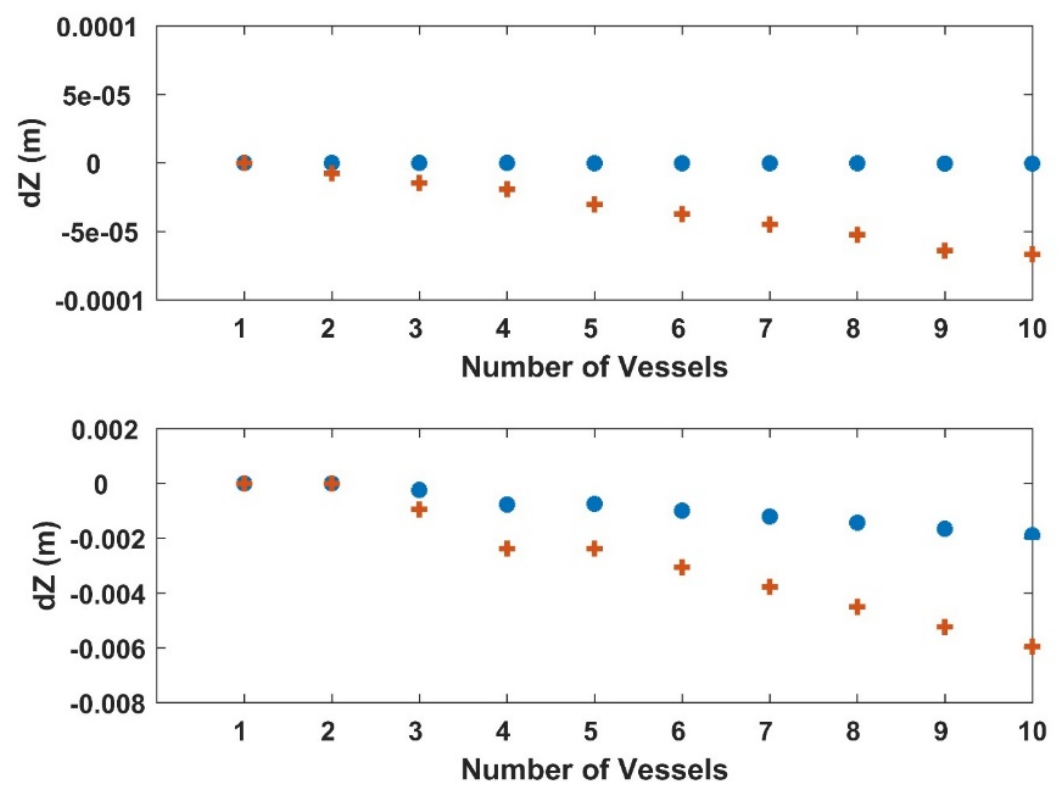

Figure 9. Wake-induced bed elevation change as a function of the number of vessels entering the study area (top panel: station $b$ of transect 1 ; bottom panel: near station a of transect 2 . The vessel sailing speed is 15 knots (circles for small vessels and plus signs for large vessels).

\section{Conclusions}

We studied the characteristics of ship wakes in Jamaica Bay by conducting short-time Fourier transform, spectrogram analysis using existing measurements of water surface levels. Our analysis showed the existence of various wake components including leading wave component (LW) and low frequency component (LW) along the typical kelvin wake, divergent, and transvers components. These wake components have longer wave lengths, compared to wind waves, and thus could reach shallow waters that are not reachable by wind waves. The patterns observed in wake characteristics were then used to evaluate a numerical phase-resolving wave model that we utilized to study wake transformation in the bay and wake-induced morphological changes. The modeled wake spectrograms compared well with the field data.

Next, we implemented the wave model to perform a series of numerical experiments to study the potential impacts of ship wakes on the bed elevation change for marsh islands Big Egg and Little Egg. The experiments accounted for various vessel sizes and sailing speeds. We found that the cumulative effect of ship wakes is to generate erosion spots near the shipping channels, especially near the edge of 
mudflats and marshes. The cumulative erosion accelerates as the number of vessels passing through the study area increases. For example, the cumulative erosion after the passage of five vessels was two to three times smaller than that after the passage of ten vessels. We also found that, regardless of the vessel size, while slow moving vessels result in negligible changes in the bed elevation, vessels that move with a higher sailing speed result in a cumulative bed elevation change, in specific, erosion in shallow areas in the vicinity of deep shipping channels.

The present study revealed the potential morphological impacts of ship wakes on marshes in Jamaica Bay. The results presented here have some limits which should be addressed in the future studies. Uncertainties due to the presence of cohesive sediments, which are neglected in this study, should be investigated. Future studies should also evaluate the effects of sediment transport formulae and nonuniform sediments on modeled morphological changes in the study area. The performance of the wave model for ship wake induced morphological changes is not evaluated because of a lack of measurements in Jamaica Bay. We suggest future studies to collect field data to inform numerical model calibration and validation. Among such field data are wake measurements along with a record of vessel information (e.g., size and sailing speed), sediment transport, bed elevation change, and marsh edge position.

Author Contributions: H.E.S. analyzed ship wake measurements and performed numerical simulations. R.M. designed the project and supervised numerical simulations and analysis. All authors have read and agreed to the published version of the manuscript.

Funding: This research received no external funding.

Acknowledgments: We would like to thank Robert Chant and Elias Hunter from Rutgers University for providing us with the water surface measurements in Jamaica Bay. The authors also thank two anonymous reviewers for their constructive comments.

Conflicts of Interest: The authors declare no conflict of interest.

\section{Appendix A}

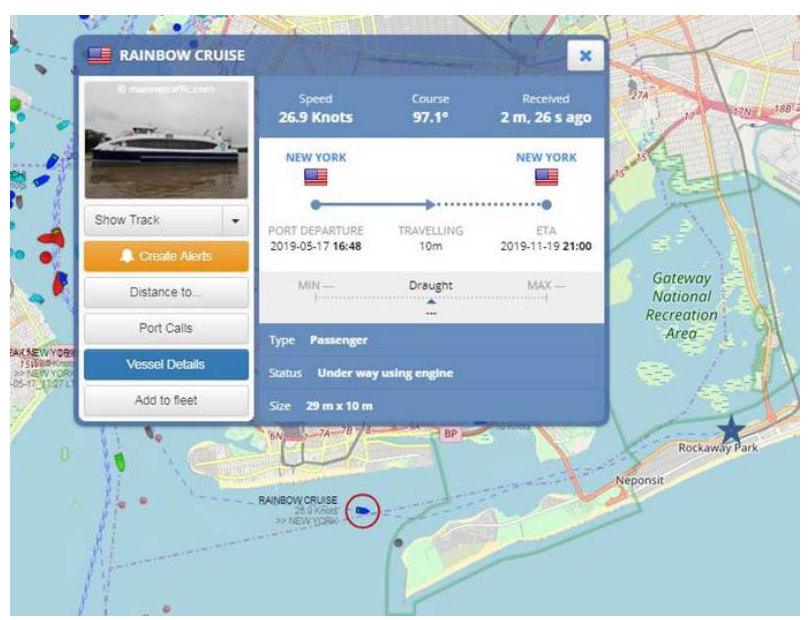

Figure A1. Rainbow Cruise (red circle) sailing to Rockaway Ferry Landing Point (blue star). Source [66]. 


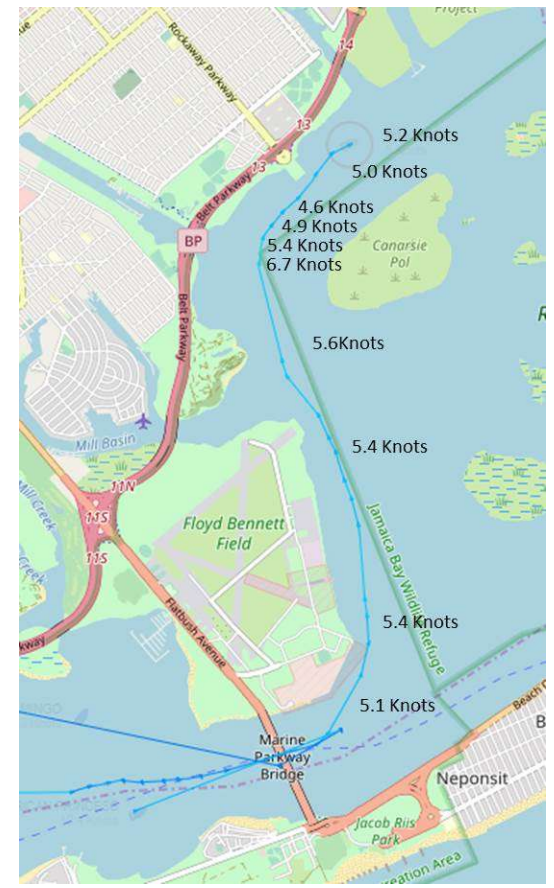

Figure A2. PINK LADY Path (shown by the blue line) and Speed. Source [66].

\section{References}

1. Hartig, E.K.; Gornitz, V.; Kolker, A.; Mushacke, F.; Fallon, D. Anthropogenic and climate-change impacts on salt marshes of Jamaica Bay, New York City. Wetlands 2002, 22, 71-89.

2. Deegan, L.A.; Johnson, D.S.; Warren, R.S.; Peterson, B.J.; Fleeger, J.W.; Fagherazzi, S.; Wollheim, W.M. Coastal eutrophication as a driver of salt marsh loss. Nature 2012, 490, 388-392. [CrossRef] [PubMed]

3. Weston, N.B. Declining sediments and rising seas: An unfortunate convergence for tidal wetlands. Estuar. Coasts 2014, 37, 1-23. [CrossRef]

4. Kirwan, M.L.; Megonigal, J.P. Tidal wetland stability in the face of human impacts and sea level rise. Nature 2013, 504, 53-60. [CrossRef] [PubMed]

5. Ganju, N.K.; Kirwan, M.L.; Dickhudt, P.J.; Guntenspergen, G.R.; Cahoon, D.R.; Kroeger, K.D. Sediment transport-based metrics of wetland stability. Geophysics. Res. Lett. 2015, 42, 7992-8000. [CrossRef]

6. Alizad, K.; Hagen, S.C.; Morris, J.T.; Medeiros, S.C.; Bilskie, M.V.; Weishampel, J.F. Coastal wetland response to sea-level rise in a fluvial estuarine system. Earth's Future 2016, 4, 483-497. [CrossRef]

7. Alizad, K.; Hagen, S.C.; Medeiros, S.C.; Bilskie, M.V.; Morris, J.T.; Balthis, L.; Buckel, C.A. Dynamic responses and implications to coastal wetlands and the surrounding regions under sea level rise. PLoS ONE 2018, 13, e0205176. [CrossRef]

8. Smith, J.M.; Bryant, M.A.; Wamsley, T.V. Wetland buffers: Numerical modeling of wave dissipation by vegetation. Earth Surf. Process. Landf. 2016, 41, 847-854. [CrossRef]

9. Marsooli, R.; Orton, P.M.; Mellor, G. Modeling wave attenuation by salt marshes in Jamaica Bay, New York, using a new rapid wave model. J. Geophys. Res. Ocean. 2017, 122, 5689-5707. [CrossRef]

10. New York City Department of Environmental Protection. Jamaica Bay Watershed Protection Plan, Volume I; New York City Department of Environmental Protection: New York, NY, USA, 2007.

11. Campbell, A.; Peteet, D. Saltmarsh Change Analysis of Jamaica Bay with Satellite Imagery; Webinar Presentation at Research of Jamaica Bay Webinar Series; Science and Resilience Institute: Jamaica Bay, NY, USA, 2018.

12. Campbell, A.; Peteet, D. Sediment History Reconstruction in Understanding the Ecosystem of Jamaica Bay; Webinar Presentation at Research of Jamaica Bay Webinar Series; Science and Resilience Institute: Jamaica Bay, NY, USA, 2018.

13. Psuty, N. Geomorphological Restoration and Resilience in Jamaica Bay, Gateway; Webinar Presentation at Research of Jamaica Bay Webinar Series; Science and Resilience Institute: Jamaica Bay, NY, USA, 2018. 
14. Ganju, N.K.; Chant, B. Sediment Transport and Budgets; Webinar Presentation at Research of Jamaica Bay Webinar Series; Science and Resilience Institute: Jamaica Bay, NY, USA, 2018.

15. Wang, H.C.; Chen, Q.; Hu, K.; Snedden, G.A.; Hartig, E.K.; Couvillion, B.R.; Johnson, C.L.; Orton, P.M. Numerical Modeling of the Effects of Hurricane Sandy and Potential Future Hurricanes on Spatial Patterns of Salt Marsh Morphology in Jamaica Bay, New York City; U.S. Geological Survey: Reston, VA, USA, 2017.

16. Peteet, D.M.; Nichols, J.; Kenna, T.; Chang, C.; Browne, J.; Reza, M.; Kovari, S.; Liberman, L.; Stern-Protz, S. Sediment starvation destroys New York City marshes' resistance to sea level rise. Proc. Natl. Acad. Sci. USA 2018, 115, 10281-10286. [CrossRef]

17. Anderson, F.E. The Effect of Boat Waves on the Sedimentary Processes of a New England Tidal Flat; Department of Earth Sciences, University of New Hampshire Technical Report 1: Durham, NH, USA, 1974.

18. Bauer, B.O.; Lorang, M.S.; Sherman, D.J. Estimating boat-wake-induced levee erosion using sediment suspension measurements. J. Waterw. Port Coast. Ocean Eng. 2002, 128, 152-162. [CrossRef]

19. Castillo, J.M.; Luque, C.J.; Castellanos, E.M.; Figueroa, M.E. Causes and consequences of salt-marsh erosion in an Atlantic estuary in SW Spain. J. Coast. Conserv. 2000, 6, 89-96. [CrossRef]

20. Johnson, J.W. Ship waves in navigation channels. In Proceeding of the 6th Coastal Engineering Conference; ASCE: Gainesville, FL, USA, 1957; pp. 666-690.

21. Johnson, J.W. Ship waves at recreational beaches. Shore Beach 1969, 37, 11-15.

22. Kos, S.; Bielby, S. Fast ferries decision: Seeing sense in its wake. N. Z. Law J. 1995, 202, 363-368.

23. Nanson, G.C.; von Krusentierna, A.; Bryant, E.A.; Renilson, M.R. Experimental measurements of river-bank erosion caused by boat generated waves on the Gordon River, Tasmania. Regul. Rivers Res. Manag. 1994, 9 , 1-14. [CrossRef]

24. Osborne, P.D.; Boak, E.H. Sediment suspension and morphological responses under vessel-generated wave groups: Torpedo Bay, Auckland, New Zealand. J. Coast. Res. 1999, 15, 388-398.

25. Pardy, B. Fast ferries: New equilibrium versus ecological sustainability. N. Z. Law J. 1995, 6, 202-204.

26. Parnell, K.E.; McDonald, S.C.; Burke, A.E. Shoreline effects of vessel wakes, Marlborough Sounds, New Zealand. J. Coast. Res. SI 2007, 50, 502-506.

27. Cox, R.; Wadsworth, R.A.; Thomson, A.G. Long-term changes in salt marsh extent affected by channel deepening in a modified estuary. Cont. Shelf Res. 2003, 23, 1833-1846. [CrossRef]

28. Sorensen, R.M. Ship-generated waves. In Advances in Hydroscience; Elsevier: Amsterdam, The Netherlands, 1973; Volume 9, pp. 49-83.

29. Glamore, W.C. A Decision Support Tool for Assessing the Impact of Boat Wake Waves on Inland Waterways. In Proceedings of the International Conference on Coastal and Port Engineering in Developing Countries, Dubai, UAE, 24-28 February 2008; p. 20. Available online: http://pianc.org (accessed on 24 February 2008).

30. Zabawa, C.; Ostrom, C. The Role of Boat Wakes in Shoreline Erosion in Anne Arundel County, Maryland; Final Report to the Coastal Resources Division; Maryland Department of Natural Resources: Annapolis, MD, USA, 1980.

31. FitzGerald, D.; Allen, J.; Rosen, P.S. Boat Wake Impacts and Their Role in Shore Erosion Processes, Boston Harbor Islands National Recreation Areas; Natural Resource Report NPS/NERO/NRR-2011/403; National Park Service: Fort Collins, CO, USA, 2011.

32. Hofmann, H.; Lorke, A.; Peeters, F. Wind and ship-induced resuspension in the littoral zone of a large lake. Water Resour. Res. 2011, 47, 1-12. [CrossRef]

33. Schwimmer, R.A. Rates and processes of marsh shoreline erosion in Rehoboth Bay, Delaware, U.S.A. J. Coast. Res. 2001, 17, 672-683.

34. Houser, C. Relative importance of vessel-generated and wind waves to salt marsh erosion in a restricted fetch environment. J. Coast. Res. 2010, 26, 230-240. [CrossRef]

35. Didenkulova, I.; Sheremet, A.; Torsvik, T.; Soomere, T. haracteristic properties of different vessel wake signals. J. Coast. Res. 2013, 65, 213-218. [CrossRef]

36. Pethiyagoda, R.; Moroney, T.J.; Macfarlane, G.J.; Binns, J.R.; McCue, S.W. Time-frequency analysis of ship wave patterns in shallow water: Modelling and experiments. Ocean Eng. 2018, 158, 123-131. [CrossRef]

37. Waldman, J. Research Opportunities in the Natural and Social Sciences at the Jamaica Bay Unit of Gateway National Recreation Area; Report Prepared for National Park Service, Jamaica Bay Institute: Brooklyn, NY, USA, 2008.

38. Marsooli, R.; Orton, P.M.; Fitzpatricl, J.; Smith, H. Residence Time of a Highly Urbanized Estuary: Jamaica Bay, New York. J. Mar. Sci. Eng. 2018, 6, 44. [CrossRef] 
39. NYCDEP. Category 2, Restoration Ecology: Objectives, Current Programs, and Potential Management Strategies; New York City Department of Environmental Protection: New York, NY, USA, 2007; Volume 2, chapter 4.

40. GNRA; National Park Service, US Department of Interior; Jamaica Watershed Protection Plan Advisory Committee. An Update on the Disappearing Salt Marshes of Jamaica Bay; National Park Service: New York, NY, USA, 2007.

41. Kelvin, W. On the waves produced by a single impulse in water of any depth. Proc. R. Soc. Lond. 1887, 42, 80-83.

42. Rabaud, M.; Moisy, F. Ship wakes: Kelvin or Mach angle? Phys. Rev. Lett. 2013, 110, 214503. [CrossRef]

43. Darmon, A.; Benzaquen, M.; Raphaël, E. Kelvin wake pattern at large Froude numbers. J. Fluid Mech. 2014, 738, R3. [CrossRef]

44. Torsvik, T.; Soomere, T.; Didenkulova, I.; Sheremet, A. Identification of ship wake structures by a time-Frequency method. J. Fluid Mech. 2015, 765, 229-251. [CrossRef]

45. Torsvik, T.; Herrmann, H.; Didenkulova, I.; Rodin, A. Analysis of ship wake transformation in the coastal zone using time-frequency methods. Proc. Est. Acad. Sci. 2015, 64, 379-388. [CrossRef]

46. Shi, F.; Kirby, J.T.; Tehranirad, B.; Harris, J.C. FUNWAVE-TVD, Documentation and Users' Manual; Research Report, CACR-1103; University of Delaware: Newark, DE, USA, 2011.

47. Chen, Q. Fully nonlinear Boussinesq-type equations for waves and currents over porous beds. J. Eng. Mech. 2006, 132, 220-230. [CrossRef]

48. Kennedy, A.B.; Kirby, J.T.; Chen, Q.; Dalrymple, R.A. Boussinesq-type equations with improved nonlinear performance. Wave Motion 2001, 33, 225-243. [CrossRef]

49. Shi, F.; Malej, M.; Smith, J.M.; Kirby, J.T. Breaking of Ship Bores in a Boussinesq-type Ship-Wake Model. Coast. Eng. 2018, 132, 1-12. [CrossRef]

50. Ertekin, R.C.; Webster, W.C.; Wehausen, J.V. Waves Caused by a Moving Disturbance in a Shallow Channel of Finite Width. J. Fluid Mech. 1986, 169, 275-292. [CrossRef]

51. Wu, T.Y. Generation of Upstream Advancing Solitons by Moving Disturbances. J. Fluid Mech. 1987, 184, 75-99. [CrossRef]

52. Torsvik, T. Long Wave Models with Application to High Speed Vessels in Shallow Water. Ph.D. Thesis, University of Bergen, Bergen, Norway, 2006.

53. Malej, M.; Shi, F.; Smith, J.M. Modeling Ship-Wake-Induced Sediment Transport and Morphological Changes-Sediment Module in FUNWAVE-TVD; ERDC/CHL CHETN-VII-20; U.S. Army Engineer Research and Development Center: Vicksburg, MS, USA, 2019.

54. Rijn, L.C. Sediment Pick-Up Functions. J. Hydraul. Eng. 1984, 110, 1494-1502. [CrossRef]

55. Cao, Z. Equilibrium Near-Bed Concentration of Suspended Sediment. J. Hydraul. Eng. 1999, 125, 1270-1278. [CrossRef]

56. Renfro, A.; Cochran, J.K.; Hirschberg, D.J.; Goodbred, S.L. Natural Radionuclides (234Th, 7Be and $210 \mathrm{~Pb}$ ) as Indicators of Sediment Dynamics in Jamaica Bay, New York; Natural Resource Technical Report NPS/NERO/NRTR-2010/324; U.S. Department of the Interior National Park Service: Fort Collins, CO, USA, 2010.

57. Meyer-Peter, E.; Müller, R. Formulas for Bed-Load Transport. In Proceedings of the 2nd meeting of the International Association for Hydraulic Structure Research, Stockholm, Sweden, 7 June 1948; The International Association for Hydro-Environment Engineering and Research (IAHR): Delft, The Netherlands; pp. 39-64.

58. Hu, K.; Chen, Q.; Wang, H.; Harting, E.K.; Orton, P. Numerical modeling of salt marsh morphological change induced by Hurricane Sandy. J. Coast. Eng. 2017, 132, 63-81. [CrossRef]

59. Karambas, T.V. Prediction of sediment transport in the swash-zone by using a nonlinear wave model. Cont. Shelf Res. 2006, 26, 599-609. [CrossRef]

60. Othman, I.K.; Baldock, T.E.; Callaghan, D.P. Measurement and modelling of the influence of grain size and pressure gradient on swash uprush sediment transport. Coast. Eng. 2014, 83, 1-14. [CrossRef]

61. Elder, J.W. The dispersion of marked fluid in turbulent shear flow. J. Fluid Mech. 1959, 5, 544-560. [CrossRef]

62. Splinter, K.D.; Holman, R.A.; Plant, N.G. A behavior-oriented dynamic model for sandbar migration and 2DH evolution. J. Geophys. Res. 2011, 116, C01020. [CrossRef]

63. Tehranirad, B.; Kirby, J.T.; Shi, F. Does Morphological Adjustment during Tsunami Inundation Increase Levels of Hazard? Research Report No. CACR-16-02; Center of Applied Coastal Research, Department of Civil and Environmental Engineering, University of Delaware: Newark, DE, USA, 2016. 
64. Kobayashi, N.; Lawrence, A.R. Cross-Shore Sediment Transport under Breaking Solitary Waves. J. Geophys. Res. 2004, 109, C03047. [CrossRef]

65. Pintado-Patino, J.C. Procesos Dinamicos en la Zona de Swash Un Estudio Integral. Ph.D. Thesis, Univesidad Nacional Autonoma de Mexico, Mexico City, Mexico, 2017.

66. Marine Traffic. Available online: www.marinetraffic.com (accessed on 6 July 2019).

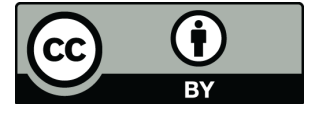

(C) 2020 by the authors. Licensee MDPI, Basel, Switzerland. This article is an open access article distributed under the terms and conditions of the Creative Commons Attribution (CC BY) license (http://creativecommons.org/licenses/by/4.0/). 